\title{
Biological efficiency profiles over the lactation period in multiparous high-producing dairy cows under divergent production systems
}

\author{
S. A. Ross $^{1}$, M. G. G. Chagunda ${ }^{1}$, C. F. E. Topp ${ }^{1}$, and R. Ennos ${ }^{2}$ \\ ${ }^{1}$ Scotland's Rural College (SRUC), Edinburgh, UK \\ ${ }^{2}$ School of Biological Sciences, University of Edinburgh, Edinburgh, UK \\ Correspondence to: M. G. G. Chagunda (mizeck.chagunda@sruc.ac.uk)
}

Received: 4 October 2014 - Accepted: 6 March 2015 - Published: 26 March 2015

\begin{abstract}
The study examined variation in energetic-efficiency profiles among production systems and cow parities. Further, the correlation between cows' body condition score (BCS) and energetic efficiency over the lactation period was determined. Biological efficiency was defined using four measures of production efficiency and two measures of energetic efficiency. The following were measures of energetic efficiency: the net energy intake required to produce $1 \mathrm{~kg}$ milk solids $\left(\mathrm{NE}_{\text {in }} / \mathrm{MS}\right)$ and the proportion of net energy utilized for milk production after accounting for maintenance $\left(\mathrm{NE}_{\text {lact }} /\left(\mathrm{NE}_{\mathrm{in}}-\mathrm{NE}_{\mathrm{m}}\right)\right)$. Seven years of data were gathered from a total of 595 Holstein-Friesian cows in a long-term genetics $\times$ feeding-management interaction project. Two feeding regimes - High forage (HF) and Low forage (LF) - were applied to each of two genetic lines (Control (C) and Select (S)), giving four dairy production systems: Low Forage Control (LFC), Low Forage Select (LFS), High Forage Control (HFC) and High Forage Select (HFS). LFS was the most efficient system using all measures. Variation in the rate and scale of change at which the cows' energetic efficiency declined over lactation was significantly different $(P<0.001)$ amongst different dairy production systems and parities. Loss of efficiency over the lactation period was lower in Select cows than in Control cows and increased with parity. The trajectory of energetic-efficiency profiles was influenced by cow genetic line, and yet the level of the efficiency profile was influenced by the feeding regime. There was a strong relationship between BCS and energetic efficiency. Continued in situ monitoring of cows' biological efficiency may enable optimal management of dairy systems.
\end{abstract}

\section{Introduction}

Traditionally, the demand for increased milk production has been met through achieving higher stocking rates or higher productivity per cow (Dillon et al., 1995). These changes necessitate an increase in animal feed requirements, and hence the efficiency of converting feed into milk is of considerable importance (Coleman et al., 2010). With the current focus on the efficient use of resources and the additional pressure of minimizing the environmental impacts of dairy systems, increasing productivity through better nutrition and genetic selection is of further significance. For many years most genetic selection indices worldwide focussed primarily on increasing milk production (Miglior et al., 2005). Ingvartsen et al. (2003) highlighted that continued selection for higher milk yield was unfavourably associated with production diseases such as mastitis across a range of dairy cattle breeds. Other studies have similarly indicated a negative association with animal performance and fertility (Pryce et al., 1999; Veerkamp et al., 2001). Coffey et al. (2004) reported that cows selected for maximum milk fat plus protein content lost significant amounts of weight and body energy over three lactations. This indicates that successive selections for high milk yields have predisposed cows to utilize body energy reserves to support lactation and these are not then fully replaced, in turn leading to fertility and health problems (Pryce et al., 2004; Pollott and Coffey, 2008). Any unfavourable association with health and fertility traits may lead to high involuntary-culling rates, potentially undermining gains achieved in productivity. 
Examining the biological efficiency of cows' performance throughout lactation, together with animal traits such as milk yield and involuntary-culling rate, provides a measure of the sustainability of dairy production systems. In this study, biological efficiency meant production and energetic efficiency. There are many ways to define the production efficiency of dairy systems. Commonly used gross production efficiency measures include daily milk yield, milk yield per unit of dry matter consumed and daily milk solids yield per unit of cow bodyweight (Britt et al., 2003; Prendiville et al., 2009; Coleman et al., 2010). Accounting for this weight change prevents animals losing body condition from appearing more efficient than they would be in reality (Coleman et al., 2010). Other studies have examined efficiency in terms of either the cow's net energy intake or its energy balance (Coffey et al., 2004; Friggens et al., 2007; Prendiville et al., 2011). It is important to ascertain that these different measures employed reflect the relative efficiency of different dairy production systems in the same way. Prendiville et al. (2011) reported the variation that existed between different breeds in terms of production and energetic-efficiency profiles over the stages of lactation. Yan et al. (2006) demonstrated that energetic efficiency of different breeds maintained under certain feeding regimes varied with different levels of concentrate in the diet. However, there is still need to better understand the efficacy and consistency of different assessment criteria for biological efficiency (Phuong et al., 2013). Furthermore, characteristics of efficiency profiles may vary within dairy production systems. The objectives of the present study were to examine how different measures of biological efficiency ranked in different dairy production systems, to investigate the differences in energetic-efficiency profiles of different production systems and parities; and to determine the relationship between cows' body condition and energetic efficiency over the lactation period.

\section{Materials and methods}

\subsection{Dairy production systems}

Data were obtained from the Langhill herd of HolsteinFriesian cows at Scotland's Rural College (SRUC) Dairy Research Centre, Crichton Royal Farm, Dumfries. Cows were part of a long-term genetic and management systems project, incorporating specifics of four distinct dairy production systems within a conventional farm. Animals were under two feeding regimes: High Forage (HF) and Low Forage (LF). A total mixed ration (TMR) comprising three forages and a purchased feed blend of concentrates was used. The HF feeding regime provided $75 \%$ by dry matter (DM) from forage, and the purchased blend for HF contained rapeseed meal, wheat and barley distillery grains. HF cows grazed ryegrass pasture when available in summer. By contrast, animals on LF were fully housed all year-round and fed a TMR comprising $45 \%$ of DM from forage, with $55 \%$ from concen- trates. The purchased LF blend contained wheat, distillery grains, sugar beet pulp molasses, soya meal and minerals (Chagunda et al., 2009). Characteristics of the two rations fed were as follows: $349 \pm 44 \mathrm{~g} \mathrm{~kg}^{-1}$ (mean \pm SD) DM content and $10.8 \pm 0.7 \mathrm{MJ} \mathrm{kg}^{-1}$ metabolizable-energy (ME) content for $\mathrm{HF}$, and $426 \pm 48 \mathrm{~g} \mathrm{~kg}^{-1} \mathrm{DM}$ and $11.7 \pm 0.7 \mathrm{MJ} \mathrm{kg}^{-1} \mathrm{ME}$ for LF. Mixed-feed rations offered to all groups when housed were formulated from the same conserved forages, and only one ration was offered within each system. Cows were fed ad libitum, and the daily TMR intake of individual lactating cows was recorded using automated Hoko feeding gates (Insentec BV, Marknesse, the Netherlands). Samples of all forages and rations were analysed weekly at the SRUC Analytical Laboratory.

Within each feeding regime, animals comprised two contrasting genetic lines; Control (C) line were animals of average UK genetic merit for milk fat plus protein content, and Select (S) animals represented the top $5 \%$ of UK genetics (Pryce et al., 1999). The $2 \times 2$ factorial experiment resulted in four divergent production systems - Low Forage Control (LFC), Low Forage Select (LFS), High Forage Control (HFC) and High Forage Select (HFS). Animals were managed in the four production systems for three lactations, with year-round calving, and herd numbers were maintained at approximately 50 cows in each system. Cows were milked three times daily, received equal health and insemination treatment, and were managed by the same herdsman. The milk yield was recorded at every milking, while milk fat and protein were analysed on 1 day per week. Animal body weights were recorded after every milking. The body condition score (BCS) was recorded weekly by tactile appraisal, on a scale of 0.0 (thin) to 5.0 (fat), with increments of 0.25 (Mulvany, 1977).

\subsection{Data}

The data used were from a period of 7 calendar years, from 2004 to 2010, and from 595 cows of which 415 had repeat lactations. Over the period there were 149829 validated individual daily records each for daily milk yield and animal bodyweight. Fewer validated feed intake records were available for HF as these cows were not receiving the TMR in the summer. Dry-matter intake (DMI) of HF cows grazing pasture was estimated by applying an equation by NRC (2001), following the method of Bell et al. (2010). Individual weekly averages for lactating cows' daily milk yield, daily milk solids (fat plus protein), daily DMI and bodyweight were used in determining production efficiency.

\subsection{Biological efficiency}

Biological efficiency was assessed using four measures of production efficiency and two measures of energetic efficiency. The measures of production efficiency were as follows: daily energy-corrected milk yield per $100 \mathrm{~kg}$ of 
Table 2. Descriptive statistics for performance traits of lactating cows in Langhill systems.

\begin{tabular}{|c|c|c|c|c|c|c|c|c|c|}
\hline \multirow[t]{3}{*}{ Trait $^{1}$} & \multirow[t]{3}{*}{ Units } & \multicolumn{8}{|c|}{ Dairy production system ${ }^{2}$} \\
\hline & & \multicolumn{2}{|c|}{ LFC } & \multicolumn{2}{|c|}{ LFS } & \multicolumn{2}{|c|}{ HFC } & \multicolumn{2}{|c|}{ HFS } \\
\hline & & mean & SD & mean & SD & mean & SD & mean & SD \\
\hline MY & $\mathrm{kg} \mathrm{cow}^{-1}$ & 29.2 & 4.45 & 34.8 & 4.95 & 22.9 & 3.55 & 26.4 & 4.46 \\
\hline $\mathrm{F}$ & $\mathrm{g} \mathrm{kg}^{-1}$ & 35.4 & 3.10 & 37.8 & 3.53 & 38.2 & 2.94 & 40.0 & 3.34 \\
\hline $\mathrm{P}$ & $\mathrm{g} \mathrm{kg}^{-1}$ & 31.8 & 1.75 & 33.7 & 1.69 & 32.1 & 1.56 & 33.5 & 1.84 \\
\hline DMI & $\mathrm{kg} \mathrm{cow}^{-1}$ & 16.9 & 4.03 & 19.4 & 4.46 & 16.6 & 4.17 & 18.5 & 4.61 \\
\hline MEI & $\mathrm{MJ} \mathrm{cow}^{-1}$ & 193 & 47.4 & 221 & 52.9 & 188 & 49.1 & 209 & 53.6 \\
\hline BW & $\mathrm{kg}$ & 607 & 76.2 & 624 & 79.3 & 573 & 75.4 & 596 & 80.5 \\
\hline BCS & dimensionless & 2.4 & 0.17 & 2.2 & 0.14 & 2.2 & 0.13 & 2.2 & 0.11 \\
\hline INV & $\%$ & 18 & 2.2 & 31 & 2.2 & 10 & 2.2 & 16 & 2.2 \\
\hline CI & day & 396 & 33.6 & 412 & 40.5 & 404 & 36.2 & 413 & 41.9 \\
\hline
\end{tabular}

${ }^{1} \mathrm{MY}$ stands for daily milk yield per cow, $\mathrm{F}$ for milk fat content, $\mathrm{P}$ for milk protein content, DMI for daily dry-matter intake, MEI for metabolizable-energy intake, BW for lactating-cow bodyweight, BCS for body condition score, INV for involuntary-culling percentage and $\mathrm{CI}$ for calving interval.

${ }^{2}$ LFC stands for Low Forage Control, LFS for Low Forage Select, HFC for High Forage Control and HFS for High Forage Select.
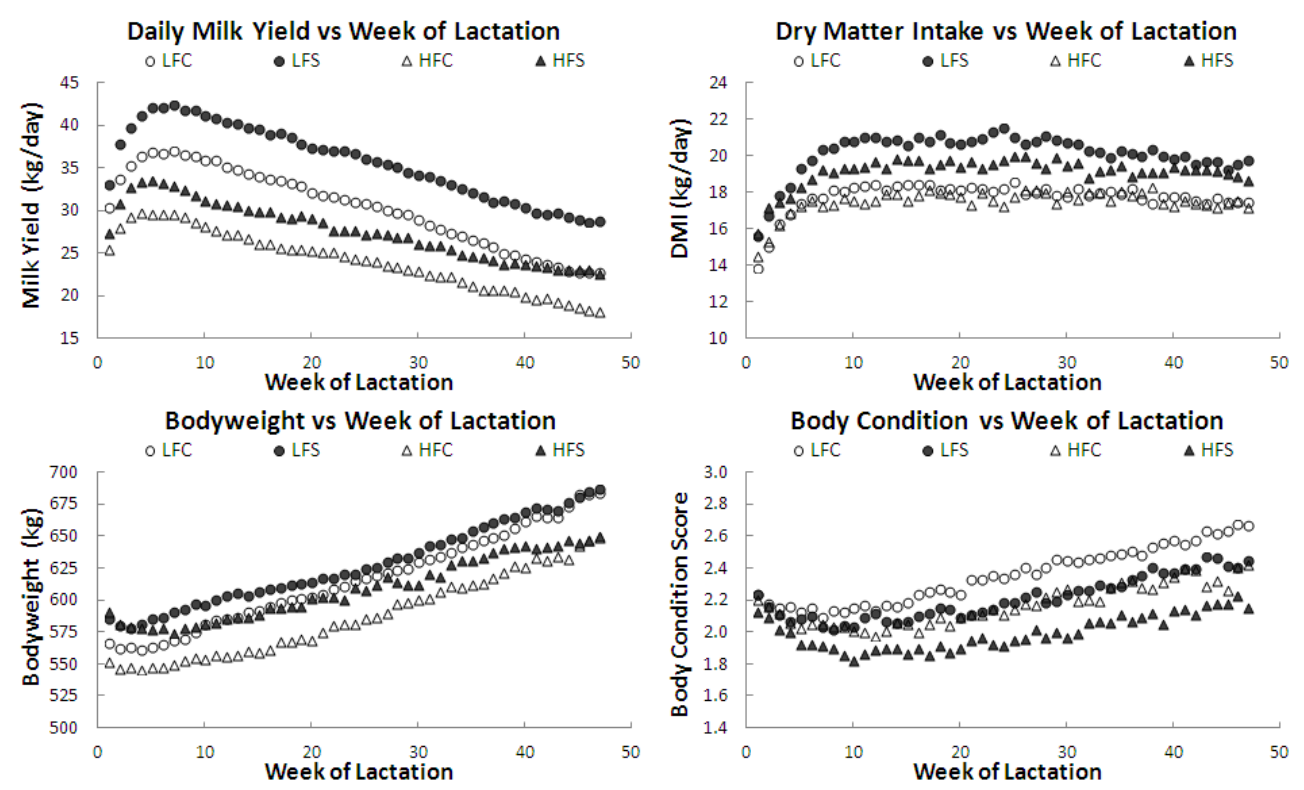

Figure 1. Daily milk yield, dry-matter intake, bodyweight and body condition score throughout lactation. LFC stands for Low Forage Control, LFS for Low Forage Select, HFC for High Forage Control and HFS for High Forage Select.

for the cows' bodyweight, ECM / BW was $38 \%$ higher for LFS than HFC. Under the same forage regime, LFS produced $20 \%$ more ECM per unit of bodyweight than LFC, and HFS produced $13 \%$ more than HFC. A similar result was observed for MS / BW, where LFS production efficiency was $41 \%$ higher than HFC. When accounting for differences in dry-matter intake, the margin between the two extreme systems was closer. However, LFS was $29 \%$ higher than HFC in terms of MS / DMI. When an adjustment for differences in calving interval and days in milk was applied to milk yield, LFS had a total annual ECM yield per cow that was $56 \%$ higher than the lowest-yielding system HFC. Production efficiency was greater in LFC than HFS using three of the measures examined; however, there was no difference between these two systems with respect to MS / BW. The effect of parity was highly significant $(P<0.001)$ in all measures except for MS / DMI.

\subsection{Energetic efficiency}

In both measures of energetic efficiency the effect of production system and week of lactation were signifi- 
Table 3. Estimated production efficiency and energetic-efficiency measures presented as least squares means ${ }^{1}$ (lsm) with standard errors of the mean (sem).

\begin{tabular}{|c|c|c|c|c|c|c|c|c|c|}
\hline \multirow[t]{3}{*}{ Measure $^{2}$} & \multirow[t]{3}{*}{ Unit } & \multicolumn{8}{|c|}{ Dairy production system ${ }^{3}$} \\
\hline & & \multicolumn{2}{|c|}{ LFC } & \multicolumn{2}{|c|}{ LFS } & \multicolumn{2}{|c|}{ HFC } & \multicolumn{2}{|c|}{ HFS } \\
\hline & & $1 \mathrm{sm}$ & sem & $1 \mathrm{sm}$ & sem & $1 \mathrm{sm}$ & sem & $1 \mathrm{sm}$ & sem \\
\hline $\mathrm{ECM} / \mathrm{BW}$ & $\mathrm{kg} 100 \mathrm{~kg}^{-1}$ & $4.5^{\mathrm{b}}$ & 0.03 & $5.4^{\mathrm{a}}$ & 0.03 & $3.9^{\mathrm{d}}$ & 0.03 & $4.4^{\mathrm{c}}$ & 0.04 \\
\hline MS / BW & $\mathrm{kg} 100 \mathrm{~kg}^{-1}$ & $0.33^{\mathrm{b}}$ & 0.003 & $0.40^{\mathrm{a}}$ & 0.003 & $0.28^{\mathrm{c}}$ & 0.002 & $0.33^{b}$ & 0.003 \\
\hline MS / DMI & $\mathrm{g} \mathrm{kg}^{-1}$ & $0.12^{\mathrm{b}}$ & 0.002 & $0.13^{\mathrm{a}}$ & 0.002 & $0.10^{\mathrm{d}}$ & 0.002 & $0.11^{\mathrm{c}}$ & 0.002 \\
\hline Adj ECM & $\mathrm{kg} \mathrm{cow}^{-1}$ & $8892^{\mathrm{b}}$ & 18.5 & $10822^{\mathrm{a}}$ & 18.7 & $6910^{\mathrm{d}}$ & 19.0 & $7989^{\mathrm{c}}$ & 19.9 \\
\hline $\mathrm{NE}_{\text {in }} / \mathrm{MS}$ & $\mathrm{MJ} \mathrm{kg}^{-1}$ & $73.4^{\mathrm{b}}$ & 0.79 & $66.2^{\mathrm{d}}$ & 0.8 & $76.9^{\mathrm{a}}$ & 0.78 & $71.3^{\mathrm{c}}$ & 0.82 \\
\hline $\mathrm{NE}_{\text {lact }} /\left(\mathrm{NE}_{\mathrm{in}}-\mathrm{NE}_{\mathrm{m}}\right)$ & $\mathrm{MJ} \mathrm{MJ}^{-1}$ & $0.924^{\mathrm{b}}$ & 0.0008 & $0.937^{\mathrm{a}}$ & 0.0008 & $0.915^{\mathrm{c}}$ & 0.0008 & $0.924^{b}$ & 0.0009 \\
\hline
\end{tabular}

${ }^{1}$ Different superscripts within rows denote significant difference between levels of same variables $(P<0.001)$.

${ }^{2} \mathrm{ECM} / \mathrm{BW}$ is the daily energy-corrected milk yield per $100 \mathrm{~kg}$ bodyweight, MS / BW equals milk solids (fat plus protein) per $100 \mathrm{~kg}$ bodyweight, MS / DMI equals milk solids per kilogram dry-matter intake, Adj ECM is the total annual energy-corrected milk yield per cow adjusted for calving interval and lactation length, $\mathrm{NE}_{\text {in }} / \mathrm{MS}$ represents cows' net energy intake required to produce $1 \mathrm{~kg}$ of milk solids, and $\mathrm{NE}_{\text {lact }} /\left(\mathrm{NE}_{\mathrm{in}}-\mathrm{NE}_{\mathrm{m}}\right)$ is the proportion of net energy intake utilized for milk production after accounting for maintenance.

${ }^{3}$ LFC stands for Low Forage Control, LFS for Low Forage Select, HFC for High Forage Control and HFS for High Forage Select.

cant $(P<0.001)$. The effect of parity was also significant $(P<0.01)$. A breakdown of results for estimated energy efficiency is presented in Table 3. LFS was the most efficient system $(P<0.001)$ with respect to $\mathrm{NE}_{\text {in }} / \mathrm{MS}$ and $\mathrm{HFC}$ was the least efficient. HFC required $16 \%$ more net energy intake to produce each kilogram of milk solids than LFS. All four systems were significantly different from each other $(P<0.001)$. HFS was more efficient than LFC; the latter required $3 \%$ more net energy per kilogram milk solids. LFC required $11 \%$ more energy than LFS, and HFC required $8 \%$ more energy than HFS. The proportion of net energy available for milk production after accounting for maintenance was significantly different $(P<0.001)$ amongst all systems. LFS had the highest estimate of $\mathrm{NE}_{\text {lact }} /\left(\mathrm{NE}_{\mathrm{in}}-\mathrm{NE}_{\mathrm{m}}\right)$ and HFC the lowest; thus, both energetic-efficiency measures identified LFS as the most efficient system and HFC the least. However, in contrast to the $\mathrm{NE}_{\text {in }} / \mathrm{MS}$, there was no difference between LFC and HFS with respect to $\mathrm{NE}_{\text {lact }} /\left(\mathrm{NE}_{\mathrm{in}}-\mathrm{NE}_{\mathrm{m}}\right)$.

The interaction between production system and week of lactation was significant $(P<0.001)$ in both measures of energetic efficiency. A plot of least squares means for system against week for each energetic-efficiency measure is presented in Fig. 2. Quadratic regression lines satisfied the best fit to the data over the 330-day period examined. The trajectory of energetic-efficiency profiles was influenced by the genetics of the cows, and yet the level of efficiency profile was influenced by the feeding regime that the cows followed. This is highlighted by the fact that, despite the LFC and HFS cows having almost the same energetic efficiency at the start of the lactation period, LFC veered towards HFC while HFS veered towards LFS as the lactation period progressed. The $R^{2}$ values for the fitted regression lines are presented in Table 4 , along with the estimated overall change in energetic ef- ficiency over lactation. $\mathrm{NE}_{\text {in }}$ / MS increased throughout lactation; therefore, the production systems became less efficient as the lactation period progressed. However, the overall change differed amongst systems. Efficiency loss was lower in the Select cows, LFS and HFS than in Control cows, LFC and HFC. Over the lactation period, $\mathrm{NE}_{\text {in }} / \mathrm{MS}$ increased by $5 \%$ in LFS and $7 \%$ in HFS, while net energy requirements for LFC and HFC over the same period increased by 16 and $11 \%$ respectively. In early lactation LFC and HFS were comparable with respect to $\mathrm{NE}_{\text {in }} / \mathrm{MS}$; however, as lactation progressed, the regression lines markedly diverged. This indicated that HFS maintained a low rate of energeticefficiency change throughout lactation, while LFC rapidly lost efficiency after 20 weeks in milk. HFS became more efficient than LFC with respect to $\mathrm{NE}_{\text {in }} / \mathrm{MS}$. In both systems of Control genetic line, over $80 \%$ of the overall change in $\mathrm{NE}_{\text {in }} / \mathrm{MS}$ occurred after 20 weeks in milk. In all systems, $\mathrm{NE}_{\text {lact }} /\left(\mathrm{NE}_{\mathrm{in}}-\mathrm{NE}_{\mathrm{m}}\right)$ decreased as the lactation period progressed. LFS began lactation as the most efficient system and experienced the lowest drop in efficiency overall. The overall change was greatest in LFC, dropping by $3.9 \%$ over 330 days. Fitted curves of LFC and HFS were broadly comparable in the early phase of lactation. LFC was initially more efficient than HFS, but, from 30 weeks in milk, cows under LFC began to diverge from HFS, indicating that cows began to allocate a lower proportion of energy to lactation at an increasing rate. Across all systems and for both energeticefficiency measures, cows of parity 1 exhibited the lowest change throughout lactation, and parity 3 exhibited the greatest. The strength of the fitted curves was also lowest for parity 1 cows in all systems with respect to $\mathrm{NE}_{\text {in }} / \mathrm{MS}$, particularly in LFS where no viable fit could be applied.

Results from the correlation of BCS with energetic efficiency are presented in Table 4. Generally, the relationship 
Table 4. $R^{2}$ value of fitted polynomial lines, change in the biological energy efficiency ${ }^{1}$ over a lactation, and correlation ${ }^{2}$ between biological energy efficiency and body condition score.

\begin{tabular}{|c|c|c|c|c|c|c|c|c|c|}
\hline \multirow[t]{2}{*}{ System $^{3}$} & \multirow[t]{2}{*}{ Parity } & \multicolumn{4}{|c|}{$\mathrm{NE}_{\mathrm{in}} / \mathrm{MS}$} & \multicolumn{4}{|c|}{$\mathrm{NE}_{\text {lact }} /\left(\mathrm{NE}_{\mathrm{in}}-\mathrm{NE}_{\mathrm{m}}\right)$} \\
\hline & & Fit $R^{2}$ & $\Delta \mathrm{MJ} \mathrm{kg}^{-1}$ & $r$ & $P<$ & Fit $R^{2}$ & $\Delta \mathrm{MJ} \mathrm{MJ}^{-1}$ & $r$ & $P<$ \\
\hline \multirow[t]{4}{*}{ LFC } & 1 to 3 & 0.90 & 10.8 & 0.88 & $* * *$ & 0.95 & -0.037 & -0.97 & $* * *$ \\
\hline & 1 & 0.43 & 4.0 & 0.6 & $* * *$ & 0.84 & -0.021 & -0.92 & $* * *$ \\
\hline & 2 & 0.91 & 12.4 & 0.88 & $* * *$ & 0.96 & -0.045 & -0.94 & $* * *$ \\
\hline & 3 & 0.89 & 18.7 & 0.92 & $* * *$ & 0.97 & -0.057 & -0.97 & $* * *$ \\
\hline \multirow[t]{4}{*}{ LFS } & 1 to 3 & 0.65 & 3.3 & 0.71 & $* * *$ & 0.80 & -0.021 & -0.96 & $* * *$ \\
\hline & 1 & 0.02 & -0.1 & -0.03 & ns & 0.72 & -0.014 & -0.82 & $* * *$ \\
\hline & 2 & 0.59 & 5.5 & 0.65 & $* * *$ & 0.91 & -0.029 & -0.89 & $* * *$ \\
\hline & 3 & 0.68 & 7.0 & 0.76 & $* * *$ & 0.89 & -0.032 & -0.87 & $* * *$ \\
\hline \multirow[t]{4}{*}{ HFC } & 1 to 3 & 0.94 & 8.4 & 0.81 & $* * *$ & 0.88 & -0.029 & -0.91 & $* * *$ \\
\hline & 1 & 0.37 & 3.2 & 0.51 & $* * *$ & 0.93 & -0.024 & -0.81 & $* * *$ \\
\hline & 2 & 0.79 & 7.9 & 0.75 & $* * *$ & 0.91 & -0.031 & -0.90 & $* * *$ \\
\hline & 3 & 0.86 & 14.5 & 0.73 & $* * *$ & 0.95 & -0.048 & -0.80 & $* * *$ \\
\hline \multirow[t]{4}{*}{ HFS } & 1 to 3 & 0.77 & 4.7 & 0.39 & $* *$ & 0.87 & -0.025 & -0.73 & $* * *$ \\
\hline & 1 & 0.29 & 2.4 & 0.12 & $\mathrm{~ns}$ & 0.88 & -0.022 & -0.41 & $* *$ \\
\hline & 2 & 0.60 & 4.7 & 0.51 & $* * *$ & 0.87 & -0.026 & -0.79 & $* * *$ \\
\hline & 3 & 0.57 & 6.8 & 0.48 & $* * *$ & 0.84 & -0.032 & -0.71 & $* * *$ \\
\hline
\end{tabular}

${ }^{1} \mathrm{NE}_{\text {in }} / \mathrm{MS}$ is the cows' net energy intake required to produce $1 \mathrm{~kg}$ of milk solids and $\mathrm{NE}_{\text {lact }} /\left(\mathrm{NE}_{\mathrm{in}}-\mathrm{NE} \mathrm{E}_{\mathrm{m}}\right)$ is the proportion of net energy intake utilized for milk production after accounting for maintenance. $\Delta$ is the estimated change in respective energy efficiency measures over a standardized lactation length.

${ }^{2}$ Correlation indicated by $r$ value is Pearson product-moment correlation coefficient; *** indicates $P<0.001, * *$ indicates $P<0.01$,

* indicates $P<0.05$ and ns stands for not significant.

${ }^{3}$ LFC stands for Low Forage Control, LFS for Low Forage Select, HFC for High Forage Control and HFS for High Forage Select.
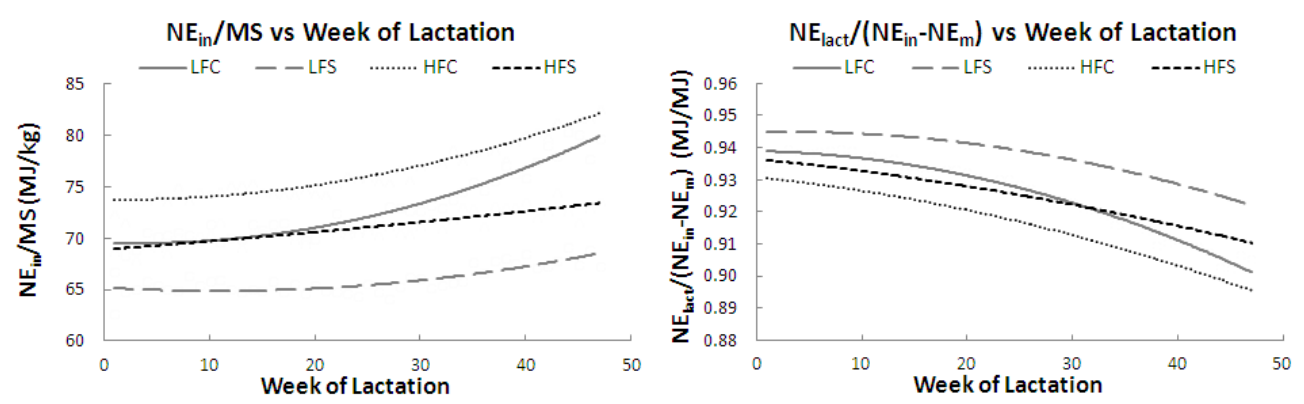

Figure 2. Fitted polynomial trend lines to biological energy efficiencies plotted against week of lactation. LFC stands for Low Forage Control, LFS for Low Forage Select, HFC for High Forage Control and HFS for High Forage Select.

was strong. The correlation coefficient $r=0.88,0.71,0.81$ (all $P<0.001)$ and $0.40(P<0.01)$ for $\mathrm{NE}_{\text {in }} / \mathrm{MS}$ in $\mathrm{LFC}$, LFS, HFC and HFS respectively, and $r=-0.97,-0.96$, -0.91 and -0.73 (all $P<0.001$ ) in $\mathrm{NE}_{\text {lact }} /\left(\mathrm{NE}_{\mathrm{in}}-\mathrm{NE}_{\mathrm{m}}\right)$. Cows of parity 1 in LFS $(r=0.03)$ and HFS $(r=0.12)$ displayed a weak relationship with respect to $\mathrm{NE}_{\text {in }} / \mathrm{MS}$. This effect was not evident with respect to $\mathrm{NE}_{\text {lact }} /\left(\mathrm{NE}_{\mathrm{in}}-\mathrm{NE}_{\mathrm{m}}\right)$, and the relationship was good for all systems in all other parities.

\section{Discussion}

The results have demonstrated that different measures of biological efficiency do not always reflect the relative efficiency of different dairy production systems in the same way. The LFS system was the most efficient of the four systems under study, and HFS was the least efficient when employing all six measures. The ranking of the remaining two systems was changeable, however, and there was no difference with respect to one production and one energetic-efficiency measure. LFC was more efficient than HFS when defined by ECM / BW, MS / DMI and Adj ECM, with HFS more efficient when defined by $\mathrm{NE}_{\text {in }} / \mathrm{MS}$. In all measures, Select cows were more efficient than Control when managed under the same feeding regime. This agrees with Coffey et al. (2004) in that cows selected for high productivity did not fully replenish body reserves mobilized in early lactation. 
This is also supported by the fact that Select cows gained less weight than Control.

The present study also demonstrated the potential for variation in energetic efficiency throughout lactation, not only within the Holstein-Friesian breed but also for cows of different parities. In both measures of energetic efficiency, cows of parity 3 and of the Control genetic line began lactation as the most efficient and finished lactation as the least efficient group under their systems. Thus these groups lost efficiency at a faster rate over lactation than those of parity 1 and 2 . In the particular case of LFS parity 1 , this system did not present any pattern over lactation with respect to $\mathrm{NE}_{\text {in }} / \mathrm{MS}$. In both measures, however, parity 1 cows started lactation as the least efficient but remained closer to their initial level of efficiency for longer, losing efficiency at a slower rate. These results suggest that primiparous cows under both LF and HF management may continue to support high production and energetic efficiency with body reserves throughout lactation. This is further supported by Sawa and Krężel-Czopek (2009), who stated that higher-yielding first-lactation cows demonstrated longer calving intervals, likely due to an increased allocation of resources to milk production.

\subsection{Production efficiency of systems}

In terms of production efficiency, the LFS system was the most efficient in all four categories assessed. This is perhaps not unexpected when considering that cows were selected for their genetic potential for production. The fact that LFS was observed to be the leading system in terms of ECM / BW, MS / BW and MS / DMI despite also having the highest average bodyweight and highest DMI of the four systems emphasizes the considerable margin between LFS and the other systems in terms of milk production. Dairy cows are known to mobilize body reserves in early lactation, coinciding with peak milk yield, and to replenish these reserves either later in lactation or during their dry period (Coffey et al., 2004; Prendiville et al., 2009). Wall et al. (2007) reported that higherproducing cows were more likely than lower producers to utilize body reserves at the peak of lactation, and selection for milk fat and protein yield has been shown to reduce bodyweight gain (Sölkner et al., 2000). This may explain why LFS was able to maintain the highest gross production per unit of bodyweight and per unit of DMI and how Select cows sustained greater production efficiency than Control when managed under the same feeding regime. However, there was no significant difference between LFC and HFS in terms of MS / BW. It is perhaps surprising to find no difference between these two systems, considering that BW was lower overall in HFS than LFC, while at the same time milk solids production was higher for HFS, yielding $12 \%$ more fat and $5 \%$ more protein per kilogram of raw milk than LFC. Daily milk yields were, however, $11 \%$ greater per cow in LFC than HFS. Therefore, the expected difference between LFC and HFS in terms of MS / BW was masked by a higher overall yield of MS in LFC owing to the higher productivity of the LF regime. This supports the argument that these measures of production efficiency may not accurately reflect the true efficiency of dairy production systems (Veerkamp et al., 1995). Measures of production efficiency employed in the present analysis (ECM / BW, MS / BW, MS / DMI) have all been defined and employed in previous studies (Prendiville et al., 2009). However, Veerkamp et al. (1995) noted that, as production efficiency is simply a ratio of two quantities (output versus input), it is therefore a measure of gross efficiency and takes no account of energy apportioned to other processes besides milk production within the body, such as maintenance. Prendiville et al. (2009) stated that, from a practical perspective, net energy must be a key determinant of production efficiency.

\subsection{Energetic efficiency throughout the lactation period}

The four production systems used in this study displayed significantly different energetic-efficiency profiles. This result highlights the potential for variation in biological efficiency that exists within the breed under different genetic selection and management conditions. The profiles for both measures of energetic efficiency were favourable in the early weeks of lactation, but efficiency was reduced steadily as lactation progressed. Thus the efficiency profiles of the four systems in the present study were broadly consistent with those previously reported for Holstein-Friesian cows throughout lactation (Prendiville et al., 2011; Veerkamp and Emmans, 1995). However, overall LFS had the lowest $\mathrm{NE}_{\text {in }} / \mathrm{MS}$, and HFS was also significantly more efficient than LFC. The efficiency profile for $\mathrm{NE}_{\text {in }} / \mathrm{MS}$ demonstrated that HFS became more efficient than LFC 20 weeks into lactation. As lactation progressed, milk yields from HFS and LFC became comparable, while DMI was consistently higher in HFS. As $\mathrm{NE}_{\text {in }} / \mathrm{MS}$ measured the efficiency of converting feed intake into milk solids, a lower rate of efficiency loss in HFS must be responsible for the crossover. Even in measures where net energy is included as a determinant of biological efficiency, the relative efficiency of two systems at a given stage of lactation may not always reflect the estimated overall efficiency of the systems in reality. The trajectory of energetic profiles distinctly demonstrated polarization along genetic lines, suggesting an aspect of genetically driven energetic efficiency. This agrees with Friggens and Newbold (2007), who demonstrated genetically driven nutrient partitioning in dairy cattle.

Cows in LFC required more net energy intake than LFS to produce a kilogram of milk solids under the same LF management regime. Under the HF regime, HFC required more net energy than HFS to produce $1 \mathrm{~kg}$ milk solids. It was noted that as lactation progressed, both the systems with Control genetic lines became less efficient at a faster rate than the two Select systems. Thus, not only were the Select systems able to continue producing at a higher level, but the disparity between energetic efficiencies of the two genetic lines 
widened as lactation progressed. Control cows maintained higher body condition throughout lactation than Select cows under the same feeding regimes. In addition, although Select cows began lactation with the heaviest bodyweight, by lactation end they were comparable with Control cows under the same regime. These observations, combined with the disparity in energetic efficiency, support the premise that animals selected for high productivity did not replenish all of their body reserves which were mobilized in early lactation (Coffey et al., 2004). In the present study, systems with Select genetic line were thus observed to maintain a consistently higher rate of production and energetic efficiency into late lactation at the expense of replacing body reserves.

There was no correlation between BCS and $\mathrm{NE}_{\text {in }} / \mathrm{MS}$ in parity 1 cows of both LFS and HFS, despite high correlation in all other parities amongst the systems. An explanation for the absence of correlation may come from considering what the units truly reflect. The selection criterion for Select cows was their potential for MS production, while BCS is essentially a measure of cows' body fat. Primiparous Select cows were still growing, and thus laying down body protein rather than fat as lactation progressed, while continuing to make a high allocation to milk production. Thus, they did not restore their body condition comparative to Control groups. Primiparous Control cows performed in a similar manner to higher-parity animals, laying down fat at the expense of allocating to production and thus increasing observed BCS as MS, and accordingly $\mathrm{NE}_{\mathrm{in}} / \mathrm{MS}$, declined. One trait that was negatively affected in the LFS group is longevity. Involuntary-culling rates in the four production systems were considerably different: $18,31,10$ and $16 \%$ for LFC, LFS, HFC and HFS respectively. Staufenbiel et al. (2003) stated that high yields could be achieved without extreme loss of body condition and cows' wellbeing. However, the high proportion of energy given to lactation by LFS cows is at the expense of their own welfare.

\subsection{In situ monitoring of biological efficiency}

Biological efficiency is not the only measure of sustainability in dairy production systems but makes a valuable contribution to addressing the question of long-term sustainability. Through monitoring the production and energetic efficiencies of individual cows over the lactation period, herd management could be optimized for biological efficiency rather than gross production. Cows displaying significantly reduced efficiency could be more readily identified. This in turn could enhance herd management decisions based on on-farm available data. Such an in situ monitoring and selection process would build on the platform already established by feeding and management regimes and contribute to breeding indices for genetic selection. Future studies should consider how selecting individual cows for biological efficiency may impact upon whole-system sustainability.
In the present study the strong correlation of changes in energetic efficiency with BCS provides equivalence to animals' body energy content throughout lactation. It is possible then that BCS is a simple tool to monitor changes in fat reserves (Garnsworthy, 2005) and may be used as a proxy to provide a practical in situ estimation of the energetic efficiency. Yaylak and Akbas (2009) recommended scoring cows weekly for the first 4 weeks of lactation and less frequently (8-weekly) for the mid- and late lactation phases to reflect herd performance. Results in the present study suggest that continued regular scoring throughout the lactation period would provide a useful indicator of individual cows' efficiency within the herd. However, assessors should receive suitable training to ensure consistency in BCS evaluation and avoid potential inter- and intra-assessor variation introduced by the subjective nature of the scoring process (Kristensen et al., 2006; Roche et al., 2009).

In conclusion, the biological efficiency profile of HolsteinFriesian cows was different under different management conditions. This was evident not only amongst different dairy production systems but also amongst cows of different parity within a system. Loss of efficiency over the period of lactation was minimal in Select genetic merit animals on lowforage feeding system. The trajectory of energetic-efficiency profiles in a lactation was influenced by the genetics of the cows, and yet the scale of the efficiency profile was influenced by the feeding regime that the cows followed. Biological efficiency may therefore be optimized through implementing and maintaining the specifics of a breeding and management system. Continued monitoring of cows' biological efficiency throughout lactation may enable dairy production systems to operate more sustainably in the future.

Acknowledgements. The authors are grateful to the farm and technical staff at Crichton Royal Farm, from where the data used in this study were obtained. This study was funded by the Scottish Government and is part of the long-term breeding and feeding systems research undertaken at the SRUC Dairy Research Centre.

Edited by: A.-E. Freifrau von Tiele-Winckler

Reviewed by: two anonymous referees

\section{References}

Bell, M. J., Wall, E., Russell, G., Morgan, C., and Simm, G.: Effect of breeding for milk yield, diet and management on enteric methane emissions from dairy cows, Anim. Prod. Sci., 50, 817826, 2010.

Britt, J. S., Thomas, R. C., Speer, N. C., and Hall, M. B.: Efficiency of Converting Nutrient Dry Matter to Milk in Holstein Herds, J. Dairy Sci., 86, 3796-3801, 2003.

Chagunda, M. G. G., Römer, D. A. M., and Roberts, D. J.: Effect of genotype and feeding regime on enteric methane, non-milk nitrogen and performance of dairy cows during the winter feeding period, Livest Sci., 122, 323-332, 2009. 
Coffey, M. P., Simm, G., Oldham, J. D., Hill, W. G., and Brotherstone, S.: Genotype and Diet Effects on Energy Balance in the First Three Lactations of Dairy Cows, J. Dairy Sci., 87, 43184326, 2004.

Coleman, J., Berry, D. P., Pierce, K. M., Brennan, A., and Horan, B.: Dry matter intake and feed efficiency profiles of 3 genotypes of Holstein-Friesian within pasture-based systems of milk production, J. Dairy Sci., 93, 4318-4331, 2010.

Dillon, P., Crosse, S., Stakelum, G., and Flynn, F.: The effect of calving date and stocking rate on the performance of springcalving dairy cows, Grass Forage Sci., 50, 286-299, 1995.

Friggens, N. C. and Newbold, J. R.: Towards a biological basis for predicting nutrient partitioning: the dairy cow as an example, Anim., 1, 87-97, 2007.

Friggens, N. C., Berg, P., Theilgaard, P., Korsgaard, I. R., Ingvartsen, K. L., Løvendahl, P. L., and Jensen, J.: Breed and Parity Effects on Energy Balance Profiles Through Lactation: Evidence for Genetically Driven Body Energy Change, J. Dairy Sci., 90, 5291-5305, 2007.

Garnsworthy, P. C.: Modern calves and heifers: challenges for rearing systems, in: Calf and heifer rearing, edited by: Garnsworthy, P. C., Nottingham, UK, 2005.

Ingvartsen, K. L., Dewhurst, R. J., and Friggens, N. C.: On the relationship between lactational performance and health: is it yield or metabolic imbalance that cause production diseases in dairy cattle? A position paper, Livest Prod. Sci., 83, 277-308, 2003.

Kristensen, E., Dueholm, L., Vink, D., Andersen, J. E., Jakobsen, E. B., Illum-Nielsen, S., Petersen, F. A., and Enevoldsen, C.: Within- and Across-Person Uniformity of Body Condition Scoring in Danish Holstein Cattle, J. Dairy Sci., 89, 3721-3728, 2006.

McDonald, P., Edwards, R. A., Greenhalgh, J. F. D., and Morgan, C. A.: Animal Nutrition, 6th ed., London, UK, 2002.

Miglior, F., Muir, B. L., and Van Doormaal, B. J.: Selection Indices in Holstein Cattle of Various Countries, J. Dairy Sci., 88, 12551263, 2005.

Mulvany, P. M.: A body condition scoring technique for use with British Friesian cows, Anim. Prod., 24, 157-158, 1977.

NRC: Nutrient Requirements of Dairy Cattle, 7th rev. ed., National Research Council, Washington, DC, USA, 2001.

Phuong, H. N., Friggens, N. C., de Boer, I. J. M., and Schmidely, P.: Factors affecting energy and nitrogen efficiency of dairy cows: A meta-analysis, J. Dairy Sci., 96, 7245-7259, 2013.

Pollott, G. E. and Coffey, M. P.: The Effect of Genetic Merit and Production System on Dairy Cow Fertility, Measured Using Progesterone Profiles and On-Farm Recording, J. Dairy Sci., 91, 3649-3660, 2008.

Prendiville, R., Pierce, K. M., and Buckley, F.: An evaluation of production efficiencies among lactating Holstein-Friesian, Jersey and Jersey $\times$ Holstein-Friesian cows at pasture, J. Dairy Sci., 92, 6176-6185, 2009.
Prendiville, R., Pierce, K. M., Delaby, L., and Buckley, F.: Animal performance and production efficiencies of Holstein-Friesian, Jersey and Jersey $\times$ Holstein-Friesian cows throughout lactation, Livest Sci., 138, 25-33, 2011.

Pryce, J. E., Nielsen, B. L., Veerkamp, R. F., and Simm, G.: Genotype and feeding system effects and interactions for health and fertility traits in dairy cattle, Livest Prod. Sci., 57, 193-201, 1999.

Pryce, J. E., Royal, M. D., Garnsworthy, P. C., and Mao, I. L.: Fertility in the high-producing dairy cow, Livest Prod. Sci., 86, 125135,2004

Roche, J. R., Friggens, N. C., Kay, J. K., Fisher, M. W., Stafford, K. J., and Berry, D. P.: Body condition score and its association with dairy cow productivity, health, and welfare, J. Dairy Sci., 92, 5769-5801, 2009.

Sawa, A. and Krężel-Czopek, S.: Effect of first lactation milk yield on efficiency of cows in herds with different production levels, Arch. Tierz., 52, 7-14, 2009.

Sjaunja, L. O., Baevre, L., Junkkarinene, L., Pedersen, J., and Setala, J.: A Nordic proposal for an energy corrected milk (ECM) formula, in: 27th Session of the International Commission for Breeding and Productivity of Milk Animals, Paris France, 1990.

Sölkner, J., Miesenberger, J., Willam, A., Fuerst, C., and Baumung, R.: Total merit indices in dual purpose cattle, Arch. Tierz., 43, 597-608, 2000.

Staufenbiel, R., Schröder, U., Gelfert, C. C., and Panicke, L.: Body condition and metabolic stability as basis of high milk yield, reproductive performance, and general health in dairy cows, Arch. Tierz., 46, 513-526 (in German), 2003.

Veerkamp, R. F. and Emmans, G. C.: Sources of genetic variation in energetic efficiency of dairy cows, Livest Prod. Sci., 44, 87-97, 1995.

Veerkamp, R. F., Emmans, G. C., Cromie, A. R., and Simm, G.: Variance components of residual feed intake in dairy cows, Livest Prod. Sci., 41, 111-120, 1995.

Veerkamp, R. F., Koenen, E. P. C., and De Jong, G.: Genetic Correlations Among Body Condition Score, Yield, and Fertility in First-Parity Cows Estimated by Random Regression Models, J. Dairy Sci., 84, 2327-2335, 2001.

Wall, E., Coffey, M. P., and Brotherstone, S.: The Relationship Between Body Energy Traits and Production and Fitness Traits in First-Lactation Dairy Cows, J. Dairy Sci., 90, 1527-1537, 2007.

Yan, T., Mayne, C. S., Keady, T. W. J., and Agnew, R. E.: Effects of Dairy Cow Genotype with Two Planes of Nutrition on Energy Partitioning Between Milk and Body Tissue, J. Dairy Sci., 89, 1031-1042, 2006.

Yaylak, E. and Akbaş, Y.: Determination of suitable timing, frequency and sample size of body condition scoring for herd management in Holstein herds, Arch. Tierz., 52, 134-142, 2009. 